\title{
EXPANSÃO DO ENSINO SUPERIOR FEDERAL - AMPLIANDO FRONTEIRAS
}

\author{
GEISA ZANINI RORATO \\ Professora da UFRGS \\ geisazr@gmail.com
}

O ensino superior federal no Brasil vivenciou um período de expansão a partir dos anos 2000 até início dos anos 2010 e teve como um de seus principais objetivos a descentralização e interiorização do ensino superior federal a partir da ampliação e criação de universidades federais, vistas como estratégicas para o desenvolvimento econômico e social de regiões menos favorecidas. Ao total foram criadas 18 novas universidades federais neste período, algumas delas com enfoque em questões relacionadas à fronteira (quatro delas) e algumas delas com campi localizados em municípios na faixa de fronteira, com maior densidade no Arco Sul.

\section{Encontros e desencontros de políticas públicas setoriais e de desenvolvimento regional}

A expansão do ensino superior federal foi implantada a partir de 2003, através do Programa Expansão Fase I. Em 2007, foi lançado o Programa de Apoio a Planos de Reestruturação e Expansão das Universidades Federais - REUNI (Brasil, 2007), ação integrante do Plano de Desenvolvimento da Educação (PDE). Esta política pode ser considerada uma política setorial, que se caracteriza por ter como objetivo ações para um setor específico (como a educação, saúde, transporte, infraestrutura, etc.). Mesmo não tendo como intenção um processo consciente de manipulação do território (Sanchez, 1992), apresenta grande potencial transformador das regiões onde se insere. Araújo (2008) considera que a abordagem setorial vem cedendo espaço para uma abordagem mais territorial e aponta como exemplo as ações do Ministério da Educação (MEC) ao fazer uma "leitura territorial com o objetivo de subsidiar os processos decisórios de localização de instituições de educação (interiorização das universidades)" (Araújo, 2008, p. 180). De fato, um dos objetivos desta política foi o de contribuir na redução das 
desigualdades regionais com expressão regional positiva pela tendência à interiorização e à desconcentração regional em relação ao ensino superior federal (Araújo, 2013).

Estas políticas setoriais convivem com políticas públicas que consideram o território como variável de ação, e que tem como objetivo a manipulação consciente do espaço. Como exemplo podemos citar a Política Nacional de Desenvolvimento Regional (PNDR) e o Programa de Desenvolvimento da Faixa de Fronteira (PDFF), ambos vinculados ao Ministério da Integração Nacional (MI).

Karam (2012) destaca a ambição do MI em internalizar a dimensão territorial no planejamento de outras políticas. A ideia era de que as demais iniciativas para resolver problemas de outras naturezas deveriam, na medida do possível, seguir critérios estabelecidos pela PNDR. Porém esta política não se consolidou como uma política de Estado e acabou não atingindo o objetivo de pautar o debate sobre o desenvolvimento regional/territorial do país. Souza Filho (2009) traça paralelos entre o processo de interiorização do ensino superior e a PNDR e considera que, apesar de desarticuladas, essas políticas convergem em pontos importantes, ao privilegiar regiões mais pobres do país.

Ao analisar as políticas setoriais e as políticas de desenvolvimento regional, é possível identificar convergências, mas ainda fica evidente a falta de articulação entre elas. A maneira individual como as políticas vêm sendo pensadas torna difícil a articulação e a integração entre as agendas e propostas de governo, refletindo na adoção de distintos recortes territoriais e espaciais para cada programa (Brasil, 2006). Assim, considera-se de fundamental importância compreender como a expansão do ensino superior federal insere-se no território e sua articulação em contexto de fronteira, já que estas políticas incidem sobre os mesmos territórios, mesmo que de forma desarticulada.

\section{Expansão do ensino superior federal - ampliando fronteiras}

A política de expansão do ensino superior federal adotada a partir dos anos 2000 ampliou fronteiras - entre regiões desenvolvidas e menos desenvolvidas, entre regiões litorâneas e o interior do país, entre estados e entre países. Neste sentido, 
o termo fronteira é entendido como uma superação de limites, construção de novas práticas.

Como consequência da acepção clássica de fronteira como limite, inventada na Europa do século XIII, cuja função inicial era demarcar territórios de diferentes estados nacionais, constitui-se no Brasil uma faixa de fronteira delimitada por uma área de 150 $\mathrm{km}$ partindo do limite com os países vizinhos, definida pela Lei $\mathrm{N}^{\mathrm{o}}$. 6.634/1979. Sobre os municípios em faixa de fronteira incide uma série de restrições quanto à implementação de infraestrutura estratégica (abertura de vias de transporte, construção de estradas internacionais, etc.) (Ruckert, 2007). Muitas regiões de fronteira acabam sofrendo com a falta de investimentos públicos, muito em função de sua posição geográfica de fronteira e pelas implicações legais advindas disso. São regiões marcadas pela precarização das condições e escassez de recursos em várias áreas como educação, saúde, transporte, habitação etc.

Mais recentemente, "as regiões na América do Sul outrora destinadas ao isolamento e/ou a políticas de contenção passam a fazer parte da agenda de políticas públicas” (Ruckert; Dietz, 2013). Destacamos principalmente a Política Nacional de Desenvolvimento Regional (PNDR) com as Mesorregiões Diferenciadas. Podemos incluir a política de expansão do ensino superior federal, cuja descentralização esteve direcionada, entre outras regiões, à "cobertura das regiões de fronteira, de hinterland, de integração e escoamento regional, ou ainda regiões portadoras de características socioculturais específicas” (Marques; Cêpeda, 2012, p. 184).

Podemos considerar que a expansão do ensino superior federal aconteceu em três grandes fases, cada uma delas com objetivos específicos (Brasil, 2014). A fase de expansão e interiorização (2003-2007) priorizou a interiorização do ensino superior federal por meio da redução das assimetrias regionais causadas pela maior concentração das universidades federais em metrópoles e regiões com maior poder aquisitivo. A fase de reestruturação e expansão (2007-2012), com ênfase na integração regional e internacional, teve como foco o processo de integração e internacionalização da educação, com destaque para a execução do Reuni. A última fase, de desenvolvimento regional e programas especiais (2012-2014), 
foi marcada pela continuidade dos programas já existentes e também de políticas específicas de integração, fixação e desenvolvimento regional (Brasil, 2014).

Destaca-se a fase de reestruturação e expansão (20072012), quando foram criadas quatro universidades que buscam a integração regional e internacional e adotam o modelo multicampi (com exceção da Universidade Federal da Integração Latino-Americana - Unila): a Universidade Federal da Fronteira Sul (UFFS), com campus nos três estados do Sul (RS, SC e PR) busca a integração entre os estados fronteiriços da região sul do Brasil; a Unila, busca integrar os países da América Latina; a Universidade Federal do Oeste do Pará (Ufopa), busca integrar a região amazônica; e a Universidade Federal da Integração Internacional da Lusofonia Afro-Brasileira (Unilab), busca integrar os países falantes da língua portuguesa em outros continentes, como a África e Ásia (Brasil, 2014).

Marques e Cêpeda (2012) consideram existir duas compreensões distintas de fronteira na política de expansão do ensino superior federal. A primeira diria respeito ao conceito clássico de fronteira limite entre países, como no caso da Unila, "que responde a proposta de integração internacional, regional e próxima do desenho do Mercosul [...] pretendendo integrar o Brasil, Argentina e Paraguai no 'encontro das três fronteiras', em Foz do Iguaçu”. Uma outra conotação de fronteira traz uma "acepção doméstica de fronteira”, como no caso da UFFS, já que é localizada na região Sul [...] ou seja, está voltada para "a integração em situações de 'bicos' fronteiriços entre unidades da Federação” (Marques; Cêpeda, 2012, p. 185).

Ao analisar os municípios em faixa de fronteira e as universidades criadas a partir de 2003, verifica-se que seis delas tem campus em municípios em faixa de fronteira (UFGD, UFTP, Ufopa, UFFS, Unipampa e UTFPR, sendo as últimas três localizadas no Arco Sul). Se considerarmos a totalidade das universidades federais (63) e campus (287), este número passa para 16 universidades ( 9 com sede de reitoria em municípios em faixa de fronteira) e 48 municípios (figura 1). 
Figura 1 - Municípios com oferta de cursos de universidades federais (2019) em faixa de fronteira e relação com município sede da Reitoria

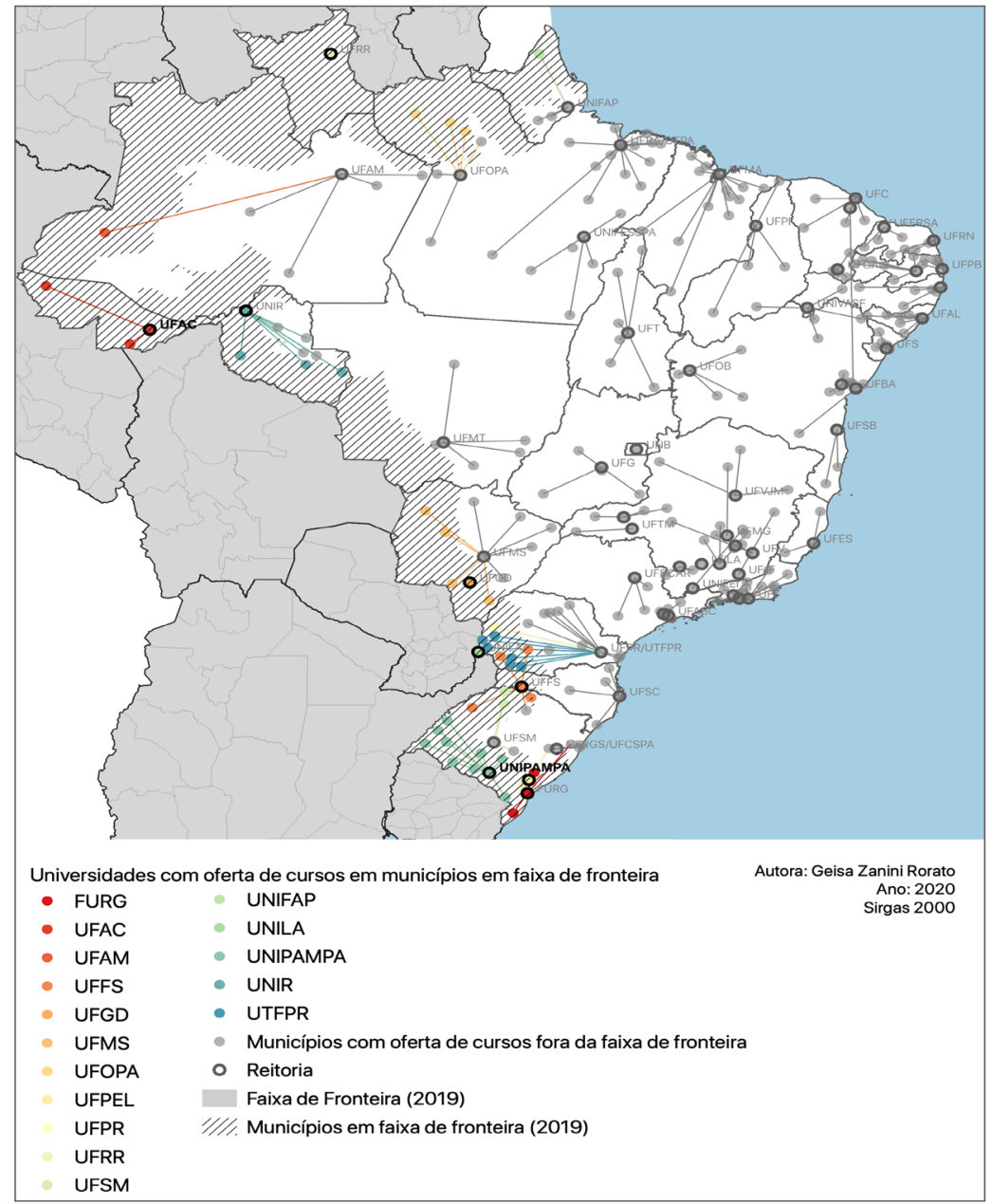

Fonte: Elaboração de Geisa Rorato com base nos Microdados do Censo do Ensino Superior Federal (INEP, 2019).

A região Sul do Brasil (RS, SC e PR) foi bastante beneficiada com a expansão do ensino superior federal, recebendo cinco novas universidades federais no período. Destacam-se em especial três delas, criadas no contexto de expansão das fronteiras (internacional e entre estados) e em faixa de fronteira (UFFS, UNIPAMPA e UNILA (figura 2). 
Figura 2 - Municípios com oferta de cursos de universidades federais (2019) em faixa de fronteira e relação com município sede da reitoria na Região Sul

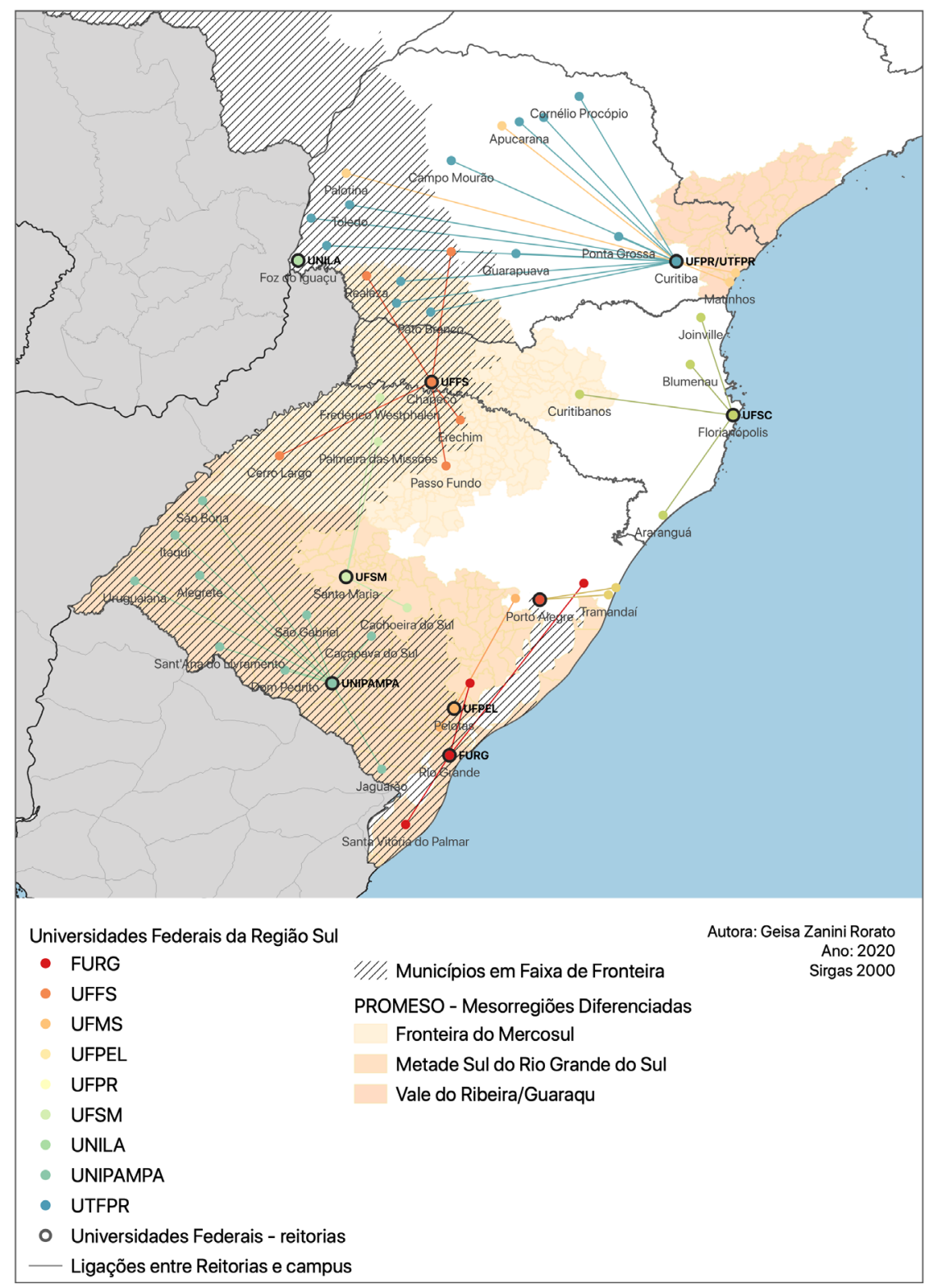

Fonte: Elaboração de Geisa Rorato com base nos Microdados do Censo do Ensino Superior Federal (INEP, 2019). 
A Unila foca sua atuação nas regiões de fronteira com países integrantes do Mercosul e demais países da América Latina (Brasil, 2010), e reserva 50\% das vagas para docentes e discentes de língua espanhola na América Latina e Caribe. Sua sede está localizada em Foz do Iguaçu (PR), junto à tríplice fronteira entre Brasil, Argentina e Paraguai. A Universidade Federal do Pampa - UNIPAM$\mathrm{PA}$, com sede em Bagé (RS), conta com outros nove campus, todos localizados em municípios em faixa de fronteira no RS. Foi criada com o objetivo de minimizar o processo de estagnação econômica da mesorregião Metade Sul do Rio Grande do Sul. A Universidade Federal da Fronteira Sul - UFFS foi criada em 2009 como resultado das reivindicações de atores regionais/locais voltada ao desenvolvimento regional com seis campus localizados majoritariamente ${ }^{1}$ na Mesorregião Grande Fronteira do Mercosul (regionalização instituída pela PNDR) e localizada em três estados². Esta estruturação não vem sem complicadores, pois ainda esbarra em questões legais e que acabam limitando de fato a maior integração entre Estados, visto ser algo novo para o próprio governo federal e governos estaduais assim como a integração internacional encontra questões legais.

\section{Universidades e fronteira - espaços de integração}

A análise da expansão do ensino superior federal permite identificar uma modificação na visão de fronteira, de uma visão tradicional de demarcação de territórios e estados nacionais (entendida como limite onde ocorrem disputas sobre a posse do território), para uma visão de fronteira como espaço de integração. Assim, a discussão atual de fronteira ultrapassa a ideia de integração com países limítrofes e expande-se.

A Unilab busca integração com os países que falam a língua portuguesa e inclusive nem se localiza em faixa de fronteira. Da mesma forma, a UFFS busca, num primeiro momento, rumo à internaciona-

1 Para maiores informações sobre a localizaçao da UFFS e sua relação com a Mesorregião Grande Fronteira do Mercosul consultar Rorato, 2016.

2 Além dela, outras duas universidades também localizam-se em mais de um estado: a Unilab (Ceará e Bahia) e a Universidade Federal do Vale do São Francisco (Univasf) (Pernambuco, Bahia e Piauí), criada em 2002. 
lização, aproximação com os países limítrofes (Argentina e Paraguai e mais ao sul, Uruguai), mas também está buscando integração com outros países, como o Haiti (através da parceria Pró-Haiti).

A questão que se coloca no momento é a continuidade destes espaços de integração. Com a redução dos investimentos e recursos para o ensino superior federal, principalmente a partir da troca de governo Dilma Rouseff e posterior aprovação da PEC do teto dos gastos públicos em 2016, muitas das universidades criadas e dos novos campus implantados estão com dificuldades para manterem suas atividades. $O$ desafio estende-se também às universidades mais antigas e já consolidadas. Outra grande dificuldade está relacionada a permanência dos alunos, visto que a ampliação e descentralização das universidades federais trouxe também modificações na forma de ingresso, possibilitando que alunos de qualquer parte do país possam acessar qualquer universidade federal.

Outros desafios esbarram nas dificuldades de gestão de campus de universidades federais em cidades menores, que podem não conseguir absorver todos os benefícios trazidos por estes novos equipamentos. Também é importante salientar as dificuldades burocráticas e legais enfrentadas por universidades com campus em mais de um estado e especialmente as que buscam a integração internacional. A interrupção da política de expansão do ensino superior federal, a redução dos gastos públicos com forte repercussão nas universidades e a reestruturação das políticas regionais trazem incertezas sobre a atuação das universidades principalmente em contextos de fronteira.

\section{Referências}

ARAÚJO, Tânia Bacelar de. Palestra magna: política pública, participação social, desenvolvimento sustentável e territórios. In: MIRANDA, Carlos; TIBURCIO, Breno (Orgs.). Articulação de políticas públicas e atores sociais. Brasília: IICA, 2008. Série Desenvolvimento Rural Sustentável, v. 8., p. 282.

ARAÚJO, Tania Bacelar de. Tendências do desenvolvimento regional recente no Brasil. IN: BRANDÃO, Carlos; SIQUEIRA, Hipólita (Orgs.). Pacto federativo, integração nacional e desenvolvimento regional. São Paulo : Editora Fundação Perseu Abramo, 2013. 208 p. 
BRASIL. Avaliação dos impactos de políticas, planos, programas e projetos no uso e ocupação do território no Brasil (Tema 2). Documentos temáticos elaborados como subsidies da proposta - PNOT. Ministério da Integração Nacional. Brasília, jun. 2006 (versão para consulta).

BRASIL. Decreto No 6.096, de 24 de abril de 2007. Institui o Programa de Apoio a Planos de Reestruturação e Expansão das Universidades Federais - REUNI. Casa Civil. Brasília, 2007. Disponível em: http://www.planalto.gov.br/ccivil_03/_ato2007-2010/2007/decreto/ d6096.htm. Acesso em: 10 out. 2016.

BRASIL. Lei $n^{\circ} 12.189 / 2010$. Dispõe sobre a criação da Universidade Federal da Integração Latino-Americana - UNILA e dá outras providências.

BRASIL. A democratização e expansão da educação superior no país 2003-2014. Ministério da Educação. Brasília, 2014. Disponível em: http://portal.mec.gov.br/index.php?option=com_docman\&view=download\&alias=16762-balanco-social-sesu-2003-2014\&Itemid=30192. Acesso em: 10 out. 2016.

KARAM, Ricardo Antônio de Souza. A economia política do desenvolvimento territorial: uma análise da diversidade institucional na agenda brasileira. 282 f. Tese (Doutorado em Políticas Públicas, Estratégias e Desenvolvimento). Programa de Pós-Graduação em Políticas Públicas, Estratégias e Desenvolvimento. Universidade Federal do Rio de Janeiro. Rio de Janeiro, 2012.

MARQUES, Antonio Carlos Henriques; CÊPEDA, Vera Alves. Um perfil sobre a expansão do ensino superior recente no Brasil: aspectos democráticos e inclusivos. Perspectivas, São Paulo, v. 42, p. 161-192, jul./dez/ 2012.

RORATO, Geisa Zanini. Expansão do ensino superior federal, atores territoriais e emergência de novas escalas de poder e gestão: A Universidade Federal da Fronteira Sul (UFFS). Tese (Doutorado em Planejamento Urbano) Programa de Pós-Graduação em Planejamento Urbano e Regional da UFRGS. Porto Alegre, 2016.

RÜCKERT, Aldomar. A política nacional de ordenamento territorial, Brasil. Uma política contemporânea em construção. Revista Electrónica de geografia y ciencias sociales, Universidade de Barcelona, v. XI, n. 245 (66), ago. 2007. 
RÜCKERT Aldomar A.; DIETZ Circe I. Integração regional, a região transfronteiriça da bacia do Rio da Prata e os projetos de infraestruturas de conexão. Confins, n. 17, 2013. Disponível em: https:// confins.revues.org/8216. Acesso em: 10 out. 2016.

SANCHEZ, Joan-Eugeni. Âmbitos de la geografia política. In:SANCHEZ, Joan-Eugeni. Geografia Política. Madrid: Editorial Síntesis. 1992.

SOUZA FILHO, Ilton da Costa. A inserção de uma instituição federal de ensino superior em uma cidade do sertão pernambucano - Serra Talhada. 90 f. Dissertação (Mestrado em Geografia) Universidade Federal de Pernambuco (UFPE). Recife, 2009. 